\title{
Anthropology and Sports
}

\author{
Ajeet Jaiswal* \\ Assistant Professor, Department of Anthropology, Pondicherry University, Puducherry, India \\ *Corresponding Author: Ajeet Jaiswal, Assistant Professor, Department of Anthropology, Pondicherry \\ University, Puducherry, India
}

\section{ABOUT THE BOOK}

The book before you is an introductory reading in Anthropology and Sport. This introductory reading was initially aimed to provide basic material in Anthropology and Sport to the beginners in the subject having no background in science. Since the fields of Anthropology especially applied aspect like physiological anthropology, sport anthropology, human growth and development part are rapidly expanding and academies are incorporating such expansions by modifying their syllabi, it was felt necessary that some important aspects of bio-cultural anthropology or anthropology of Sport hither to untouched should be included in the text.

During the last two decades we have witnessed some striking developments which have prompted the re-evaluation of many ideas. Further there has been a healthy shift of interests in favour of the applications of anthropology in human welfare especially in the field of sports. It focuses on those fields which impinge upon the story of Origin of Sport, Meaning of sports, Sports Anthropology and Human Physiology. In this venture author had two objectives in mind: firstly to bring within the easy reach of our undergraduate, post graduate, NET, SLET, State PCS, UPSE, Department of Sports (Ministry of Youth Affairs and Sports), Physical education, Sport and Anthropology students a suitable text book of Anthropology and Sport which covers most of the relevant aspects of their syllabi, and secondly to make it relevant to the beginners in the subject who have had no background in science. It is true that there are many publications including the classical works on physical anthropology, Physical Education, Sport Education etc. but these are not easily available and students are always confronted with the problem of finding a suitable publication for their purpose. Moreover, during many years of education, research and teaching author have felt the need of a text book concise enough for a one year course but no limited by omission of concepts from general bio-cultural anthropology mainly Sport Practice and Anthropometry, Human Body Composition and Somatotyping, Physical Growth, Maturation and Performance, Physical Adaptation, Environmental stress and Physical performance etc.. In view of these considerations and the fact that the applied fields of Anthropology i.e. Anthropology of Sports are rapidly expanding, the need for a suitable text book had become even more acute.

This book contains the substance of lecture delivered by me to my students which have been somewhat differently arranged and amplified by reference to additional discoveries and information's which accumulated in the mean time. The book introduces Anthropology of Sports section of biocultural anthropology as a branch of anthropology in the background of its historical development. The question of its definition is considered in detail as regards the conceptualization of anthropology in the old as well as the new world. Attempts have been made to focus on the perspectives and the approach in Anthropology of Sports part of bio-cultural anthropology in the past and the changes brought about during the course of its development to its present context. The subject matter of Anthropology of Sports is discussed in relation to other branches of Physical anthropology, Physical education and other biological sciences.

The question of the what is Anthropology, its history, Meaning of Sport in Anthropology, Kinanthropometry, its Applications and Relevance of Kinanthropometry and anthropometry are properly discussed in chapter one. This is followed by a detailed consideration of the phenomena of the Physique and Sports, choosing suitable activity for individuals with emphasis on redesigning of 
sports article. Chapter 2 is explaining information related to Origin of Sport, Archeology and Sport History, Prehistory and Early History of Sport and the Archaeological Record.

Chapter three devoted to an understanding of the concept of Culture, Cultural Approach to Sport, Work and Leisure, Play, Sport as Work or Play. The relationship and dynamics of Sport and Games, Sport and Ritual, Sport as Conflict, Sport, Recreation and Physical Education are also discussed in this chapter. The questions relating to Fundamentals of Work Physiology, Fundamentals Blood parameters during dynamic work, Thermoregulation during dynamic work, and Hormonal regulation during dynamic work is discussed in chapter four along with a brief description of Muscle structure and function, Circulatory system, Respiratory system, Fatigue, Hemodynamic and Exercise. Chapter 5 is devoted to Sport Practice and Anthropometry also focused on the phenomena of Body mass and weight, Body density, Body fat percentage, Fat mass and fat free mass, Body mass index and Somatotype.

This is followed by a description of Human Body Composition and Somatotyping in chapter six. Special attention has been paid to explain Heath-Carter somatotype method and Body Composition and Somatotyping in Sports Performance. Author has summarized the concept of Physical Growth, Maturation and Performance in chapter 7 along with a brief description of the Biological Maturation, Physical fitness testing and Interpretation.

The subject matter of Sports performance and Human Physiology, Physiological Variables That Influence Sports Performance, Mechanical Efficiency and Running, Physical Activity and Health, Maintaining Fitness and Muscular Strength, Environmental Conditions, Hydration and Endurance Exercise etc. as an important concept of research and study is considered in chapter eight.

This is followed by a discussion of Physical Adaptation and Strength Training in chapter 9. Here the concept of Benefits and risks of strength training, Physical activity and body composition in young adults, Anthropometry of mountain climbers, Physical adaptation during expeditions at high altitude is discussed in detail followed by a brief review of the Anthropometric and biomechanical characteristics of a sprinters, Sprint performance and strength assessment

This is followed by a description on Assessment of Posture, Flexibility and Physical Activity in chapter ten. Special attention has been paid to explain Curvatures and movement of the vertebral column, Measurement of posture and body shape and Flexibility measurements with goniometry. Author has summarized the concept of Environmental stress and Physical performance in chapter eleven along with a brief description of the Environment and human health, Concern on Environment and health, Natural Resources, Public Health, Eco-values and Environmental health. Special Olympics, Vision of Special Olympics and Guidelines on Worksite Prevention of Low Back Pain are very scientifically described in chapter twelve and thirteen respectively.

Throughout the book author's effort has been to make the subject matter readably comprehensible to the beginners. For those who are advanced author have added references which would help them in pursuing the topics of their interest. By quoting references author have only indicated sources of richer data. It is not an attempt to justify our statements or to acknowledge the sources of our ideas. Whatever author has written is not claimed to be original, it is only drawn from various sources and freshly digested. As such author really owe to the works of many other scientists, colleagues, predecessors and publishers whose material has been used. Author hope that the students and the teacher colleagues will find our effort useful.

It is hoped that this book will stimulate improvements in teaching and instruction strategies in Anthropology of Sports. In this way, author will have made a contribution towards furthering the education of the next generation of specialists concerned with the relation between human structure and function.

Citation: Ajeet Jaiswal. "Anthropology and Sports" International Journal of Research in Sociology and Anthropology (IJRSA), vol 5, no. 3, 2019, pp. 29-30. doi: http://dx.doi.org/10.20431/2454-8677.0503004.

Copyright: () 2019 Authors. This is an open-access article distributed under the terms of the Creative Commons Attribution License, which permits unrestricted use, distribution, and reproduction in any medium, provided the original author and source are credited. 